This paper has been published in Soil Biology \& Biochemistry 58(2013) 1-8

\title{
Labile carbon in biological soil crusts in the Tabernas desert, SE Spain
}

\author{
Isabel Miralles ${ }^{\mathrm{a}}$, Carmen Trasar-Cepeda ${ }^{\mathrm{b}}$, M. Carmen Leirós ${ }^{\mathrm{c}}$, Fernando Gil-Sotres ${ }^{\mathrm{c}^{*}}$
}

${ }^{a}$ Departamento de Desertificación y Geoecología, EEZA-CSIC, E-04230 La Cañada de San Urbano, Almería, Spain; ${ }^{b}$ Departamento de Bioquímica del Suelo, IIAG-CSIC, Apartado 122, E15780 Santiago de Compostela, Spain, and ${ }^{c}$ Departamento de Edafología y Química Agrícola, Grupo de Evaluación de la Calidad del Suelo, Unidad Asociada CSIC, Facultad de Farmacia, Universidad de Santiago de Compostela, E-15782 Santiago de Compostela, Spain.

* corresponding author; e-mail: fernando.gil@usc.es

\begin{abstract}
Decomposition processes are extremely important in biological soil crusts (BSCs). Although the effects of temperature and moisture on such processes have been widely studied, little is known about the influence of the readily metabolizable substrate (labile $\mathrm{C}$ ) and how this substrate varies in different types of BSCs. In the present study, BSCs formed by cyanobacteria (CYANO) and by lichens (DIPLOS and LEPRA) were incubated at $25{ }^{\circ} \mathrm{C}$ (optimum temperature) and different moisture levels, for evaluation of the pool of labile $\mathrm{C}$ in the crust layers. Labile $\mathrm{C}$ was estimated as the sum of $\mathrm{CO}_{2}-\mathrm{C}$ emitted and the $\mathrm{C}$ extracted with hot water $\left(80{ }^{\circ} \mathrm{C}\right)$ at the end of the incubation period. In all crusts, the relationship between emission and moisture fitted a quadratic model. For the different moisture contents, the sum of $\mathrm{CO}_{2}-\mathrm{C}$ emitted and $\mathrm{C}$ extracted with hot water converged to a constant value for each type of crust. This value, considered as the maximum content of labile $\mathrm{C}$ in the crust, was extremely high in DIPLOS, reaching up to $40 \%$ of the total organic C (TOC) initially present. In all crusts, and independently of the consumption of labile $\mathrm{C}$, simple sugars (sucrose, glucose) remained at the end of the incubation period, which suggests that these sugars may play a protective role in BSCs. The presence of mannitol suggests that the fructose released during hydrolysis of sucrose was reduced to mannitol, thus enabling electron transport during moments of intense respiratory stress. The intense respiration in DIPLOS is partly due to the metabolism of polyphenols, which are possibly derived from the growth and death of free-living fungi that proliferate during incubation of the crusts. These results demonstrate that the metabolic processes in BSCs differ depending on the type of organisms that form the crusts and that there is a high risk of $\mathrm{C}$ loss from Diploschistes BSCs after heavy rainfall events.
\end{abstract}

Key words: Soil emission; Soil biomass; Carbohydrates; Cyanobacteria; Lichens

\section{Introduction}


Biological soil crusts (BSCs) cover most of the soil surface in arid and semi-arid zones (Belnap et al., 2001), except in areas of mobile sand and areas where the soil surface is frequently disturbed. Although the climatic characteristics of these zones (low humidity, extreme temperatures) may suggest a slowing down of biological processes, the rate of decomposition in arid and semi-arid ecosystems is similar to that in mesic ecosystems, because of the interactions between abiotic and biotic processes (Stursova and Sinsabaugh, 2008). The main abiotic process involved in decomposition in arid and semi-arid zones is the photodegradation of plant remains, which occurs throughout the entire year due to the high luminosity (Austin and Vivanco, 2006). The biotic processes of decomposition (which are reflected in soil respiration) are mainly determined by climatic characteristics, and in arid environments they only occur when these characteristics favour the metabolic activity of heterotrophic organisms, mainly bacteria and fungi. The climatic characteristics also favour autotrophic emission of $\mathrm{CO}_{2}$ (generated by plant roots and photosynthetic organisms), so that respiration is intermittent in arid and semi-arid areas (Conant et al., 2000). Because of this intermittent pattern, the annual $\mathrm{CO}_{2}$ emission dynamics in arid zones are very different from those in mesic ecosystems. Therefore, there has been great interest in recent years in quantifying the $\mathrm{CO}_{2}$ emissions in order to help understand the effects of this intermittent behaviour on the carbon balance (Conant et al., 2004; Grote et al., 2010; Maestre et al., 2011; Thomas et al., 2011). Most studies have focused on the effect of climate on the metabolic activity of the BSCs. Temperature and moisture are the most widely studied factors in relation to respiration in BSCs (Castillo-Monroy et al., 2011), but studies of the effects of moisture predominate because this factor has a greater influence on respiration (Conant et al., 2000). The relationship between respiration and moisture content is usually complex (Grote et al., 2010; Castillo-Monroy et al., 2011), because respiration is greatly hindered by both extremely dry conditions and conditions close to saturation (Grote et al., 2010). Moreover, in addition to climatic parameters, emissions are also affected by topography (Sponseller and Fisher, 2008), the characteristics of the biotic community (i.e. the type of crust) (Maestre et al., 2011) and, of course, by the readily metabolizable substrate, i.e. by the so-called labile $\mathrm{C}$ content (Thomas et al., 2011).

The labile $\mathrm{C}$ pool in BSCs determines the duration of $\mathrm{CO}_{2}$ flows when the temperature and moisture are favourable for respiration (Fernandez et al., 2006; Sponseller and Fisher, 2008; Thomas et al., 2011). Although quantification of the labile $\mathrm{C}$ pool is difficult because of the rather unspecific definition ("easily mineralized substrate"), different protocols for estimating this pool have been proposed: e.g. extraction of the soil organic matter with hot or cold water, or with dilute neutral saline solutions, or by oxidation with potassium permanganate and acid hydrolysis (Leinweber et al., 1995; Sparling et al., 1998; Rovira and Vallejo, 2002; Landgraf et al., 2005, amongst others).

Estimation of the labile $\mathrm{C}$ in soil is also complicated by the fact that the amount of labile soil $\mathrm{C}$ is not constant, but varies depending on the moisture and temperature conditions to which the microbiota is exposed (Hu et al., 1997). Other factors that modify the labile $\mathrm{C}$ content, in addition to the metabolic activity of the microbiota, are the processes of physical and physicochemical disintegration of the organic remains (induced by the increased moisture) and the death of microorganisms as a result of plasmolysis induced by a sudden increase in moisture, or as a 
result of the microorganisms reaching the end of their life cycle (Fierer and Schimel, 2003; Luo and Zhou, 2006; Borken and Matzer, 2009).

Despite these problems, estimation of the labile $\mathrm{C}$ pool is essential for determining the dynamics of the carbon cycle in soil. Most research on this pool in BSCs in arid and semi-arid zones has involved field quantification of the large pulse of $\mathrm{CO}_{2}$ released after wetting dry soils (see Collins et al., 2008; Thomas et al., 2011 and references therein), and few studies have determined the labile $\mathrm{C}$ pool under laboratory conditions (Conant et al., 2000). The latter authors attempted to quantify the labile $\mathrm{C}$ pool in $\mathrm{CO}_{2}$ emission studies in which conditions were controlled until the soil respiration rate reached a steady state (op.cit). However, the amounts estimated were lower than the amounts of $\mathrm{C}$ respired by the BSCs when rewetted, which indicated an error in the method of estimating the labile $\mathrm{C}$ pool. Under field conditions, photosynthetic and decomposition processes interfere with each other, as a result of the presence of light, so that after wetting, the existing labile $\mathrm{C}$ and the recently synthesized labile $\mathrm{C}$ are both metabolized. Moreover, under arid conditions, the BSCs rapidly dry out after wetting; this inactivates the cellular metabolism, thus possibly preventing consumption of all of the labile $\mathrm{C}$ present in the BSCs. For all of the above reasons, estimation of labile $\mathrm{C}$ via respiration pulses may not be accurate and will not reflect the actual amount of metabolizable $\mathrm{C}$ in BSCs.

The aims of the present study were to quantify the labile fraction of the organic matter in the crust layers $(0-0.5 \mathrm{~cm})$ of different types of BSCs (predominated by cyanobacteria or by lichens), as well as to characterize the main components of the pool and to determine whether the metabolic strategies for labile $\mathrm{C}$ use are the same in BSCs constituted by cyanobacteria and by lichens (with photobionts other than cyanobacteria).

The working hypotheses of the study were as follows: i) the organic matter pool in BSCs can be accurately estimated by exhausting the labile or mineralizable $\mathrm{C}$, which can be achieved by incubating the crusts under conditions that impede photosynthesis and favour respiration. iii) the labile $\mathrm{C}$ is distributed between the non-mineralized labile $\mathrm{C}$ (which includes both the $\mathrm{C}$ remaining at the end of the incubation, i.e. the remnant $\mathrm{C}$, and biomass- $\mathrm{C}$ ) and the mineralized labile $\mathrm{C}$ (fraction utilized in $\mathrm{CO}_{2}$ emission) (Fig. 1), iii) the remnant $\mathrm{C}$ can be evaluated as the difference between the non-mineralized labile $\mathrm{C}$ and the biomass- $\mathrm{C}$, because the procedure used to estimate the non-mineralized labile $\mathrm{C}$ (extraction with water at $80^{\circ} \mathrm{C}$ ) will kill the microbial cells and render their components extractable (Stanier et al., 1968; Speir et al., 1986), and iv) the composition of the remnant $\mathrm{C}$ fraction will provide information about the metabolic processes that take place in the BSCs, because the compounds present in this fraction are those that have not been used during respiration.

\section{Material and methods}

\subsection{Types of samples and sampling}

BSCs at different stages of development were sampled in the Tabernas desert (Almería, SE Spain). The early successional stage BSC was a cyanobacteria-dominated BSC (CYANO), the second successional stage BSC was a lichen BSC, predominated by Diploschistes diacapsis (Ach.) Lumbsch (DIPLOS), and the BSC at the final development stage was a lichen BSC predominated by Lepraria crassissima (Hue.) Lettau (LEPRA). A detailed description of the 
area and of the biological constituents of each type of crust is provided elsewhere (Miralles et al., 2012). Each of the above-mentioned types of BSC was sampled at three closely located sites on the same day in June 2011 (i.e. when the crusts were dry). At each site, a composite sample of the crust layer $(0-0.5 \mathrm{~cm})$ was obtained by mixing 10-15 subsamples (each representative of an area about $0.1 \mathrm{ha}$ ) in the field. The samples were transported in isothermal bags to the laboratory, where they were sieved $(<4 \mathrm{~mm})$ in order to homogenize them, although this may modify the crust structure. The sieved samples were stored at $4{ }^{\circ} \mathrm{C}$ until the analyses were carried out, in all cases within 15 days of collection. A portion of each sample was air-dried and used for measurement of the general properties. The field moisture content was determined by gravimetry in an aliquot of the sample dried at $105{ }^{\circ} \mathrm{C}$ for $24 \mathrm{~h}$, and the moisture content was determined at pF 2.0 (field capacity) and pF 4.2 (permanent wilting point) as the water retained at 10 and 1500 $\mathrm{kPa}$, respectively, in undisturbed soil samples (Guitián and Carballas, 1976).

\subsection{Experimental design}

Samples of the crusts were incubated in the laboratory under different levels of moisture, in the dark, and at an optimal temperature of $25{ }^{\circ} \mathrm{C}$, in order to impede photosynthesis and maximize the metabolic activity in the BSCs.

Aliquots of each of the crusts were moistened with distilled water to produce the following moisture contents: $9.6 \%, 26.0 \%, 52.0 \%$ and $78.0 \%$, all expressed as percentages of water retained at $\mathrm{pF}$ 2.0. For each of the crust layers collected (9 samples: 3 sites and 3 types of BSC in each site), triplicate aliquots (25 g) for each level of moisture were placed in small plastic containers (height $3 \mathrm{~cm}$, basal surface area $18 \mathrm{~cm}^{2}$ ) and incubated in 11 Mason jars (height 16 $\mathrm{cm}$, basal surface area $67 \mathrm{~cm}^{2}$ ) with alkaline traps, at $25^{\circ} \mathrm{C}$ for 10 days in the dark. The jars were opened periodically to replace the air within them and to enable replacement of the alkaline trap with fresh solution. The $\mathrm{CO}_{2}$ adsorbed in the alkaline solution that was removed was measured as described below. At the end of the 10 day incubation period, the incubated soil was removed for determination of the hot water soluble fraction, the microbial biomass- $\mathrm{C}$ and the $\mathrm{B}$ glucosidase and invertase activities.

\subsection{Methods}

The methods described by Guitián and Carballas (1976) were used to determine the following: $\mathrm{pH}$ in water and in $1 \mathrm{M} \mathrm{KCl}(1: 2.5$, soil:water ratio or soil: $\mathrm{KCl}$ solution ratio), total organic carbon (TOC) content (by wet oxidation with potassium dichromate oxidation and prior elimination of carbonates) and total nitrogen (TN) content (by Kjeldahl digestion).

Microbial biomass $\mathrm{C}$ (Biomass-C) was determined by the chloroform fumigation extraction method, with $0.5 \mathrm{M} \mathrm{K}_{2} \mathrm{SO}_{4}$ as extractant, at a soil:extractant ratio of 1:4 (Vance et al., 1987). The $\mathrm{C}$ content in the extracts was estimated by potassium dichromate oxidation of an aliquot dried at $60{ }^{\circ} \mathrm{C}$. The difference in the $\mathrm{C}$ content of the extracts from fumigated and unfumigated samples was converted to biomass- $\mathrm{C}$ by dividing the value obtained by a factor $\left(K_{c}\right)$ of 0.45 (Vance et al., 1987). The results are expressed as $\mathrm{mg} \mathrm{C} \mathrm{kg}^{-1}$ of oven-dried soil.

The amount of $\mathrm{CO}_{2}$ emitted (mineralized labile $\mathrm{C}$ ) was determined by titration of the remaining $\mathrm{NaOH}$ in the alkaline traps with $\mathrm{HCl}$, after prior precipitation (with barium chloride) 
of the carbonates formed (Guitián and Carballas 1976). The $\mathrm{CO}_{2}$ titrations were carried out in triplicate throughout the incubation, so that the individual values in each case are mean values from 9 determinations. The results are expressed as $\mathrm{mg} \mathrm{CO}_{2}-\mathrm{C}$ emitted $\mathrm{kg}^{-1}$ of oven-dried soil.

The B-glucosidase activity was determined after incubation of the samples with a solution of $25 \mathrm{mM} p$-nitrophenyl- $\beta$-D-glucopyranoside and colorimetric measurement of the amount of $p$ nitrophenol released during enzymatic hydrolysis. The conditions of the determination were as follows: the buffer (MUB) $\mathrm{pH}$ was 6.0, the incubation time was $1 \mathrm{~h}$ and the released $p$ nitrophenol was extracted with $0.1 \mathrm{M}$ (Tris-hydroxymethyl-aminomethane)-NaOH (THAM$\mathrm{NaOH}$ ), pH 12 (Eivazi and Tabatabai, 1988). The B-glucosidase activity is expressed as $\mu \mathrm{mol} p$ nitrophenol $\mathrm{g}^{-1} \mathrm{~h}^{-1}$. Invertase activity was determined after incubating the sample with $35.06 \mathrm{mM}$ sucrose, as substrate, for $3 \mathrm{~h}$ at $50{ }^{\circ} \mathrm{C}$, with $2 \mathrm{M}$ acetate buffer, $\mathrm{pH} 5.5$; the reducing sugars released were determined following the method of Schinner and von Mersi (1990). The invertase activity is expressed as $\mu$ mol glucose $\mathrm{g}^{-1} \mathrm{~h}^{-1}$.

In order to determine the fraction of $\mathrm{C}$ soluble in hot water (non-mineralized labile $\mathrm{C}$ ), $50 \mathrm{ml}$ of distilled water was added to an amount of incubated sample equivalent to $5 \mathrm{~g}$ of air-dried sample, and the mixture was maintained for $18 \mathrm{~h}$ at $80{ }^{\circ} \mathrm{C}$ in a shaking water bath. The extract was then centrifuged $(3200 \times \mathrm{g}, 20 \mathrm{~min})$ and filtered through a $0.45 \mu \mathrm{m}$ membrane filter. Aliquots of the filtrate were dried at $60{ }^{\circ} \mathrm{C}$, and the total $\mathrm{C}$ content was measured in the dried extracts by oxidation with dichromate in acidic medium (Guitián and Carballas, 1976). The results are expressed in $\mathrm{mg} \mathrm{C} \mathrm{kg}^{-1}$. Total polyphenolic $\mathrm{C}$ was determined in an aliquot of the extracts by the Folin-Ciocalteu method and with tannic acid as the standard (Kuwatsova and Shindo, 1973; Rovira and Vallejo, 2002). Total sugars in the extracts were determined by the anthrone method, with glucose as the standard (Ceccanti et al., 1993).

Sugars in the water extracts were characterized by HPLC, in a HPLC system (Agilent model 1200, Waldbronn, Germany) equipped with a quaternary pump, a degassing device, an autosampler, a column thermostat system and a refraction index detector (RID). The data were recorded with Chemstation chromatographic software. Chromatographic separation was achieved by an isocratic method, with an Aminex HPX-87H column $(300 \times 7.8 \mathrm{~mm}$ internal diameter, $9 \mu \mathrm{m}$ particle size) (Bio-Rad), which was thermostated to $30{ }^{\circ} \mathrm{C}$. The mobile phase used was $0.01 \mathrm{~N} \mathrm{H}_{3} \mathrm{PO}_{4}$ with $4 \%$ tetrahydrofuran (THF). The total run time was $35 \mathrm{~min}$. The mobile phase flow rate was $0.45 \mathrm{ml} / \mathrm{min}$ throughout the analysis and the sample injection volume was $20 \mu \mathrm{l}$ (Chinnici et al., 2002). For identification and quantification of the sugars, solutions of different concentrations (between 0-100 $\mathrm{g} \mathrm{ml}^{-1}$ ) of sucrose, glucose, fructose, arabinose, mannose, galactose, xylose, mannitol, glycerol and myoinositol were run under the same conditions as the samples.

\subsection{Statistical analysis}

For each type of BSC, all data for the same property were averaged to produce a mean value, to avoid pseudo-replication. Statistical analyses (determination of means and standard deviations, application of two-sample $t$-tests to compare the difference between sample means) were performed with Statistica 6.0 (StatSoft ${ }^{\circledR}$ ) for Windows. 


\section{Results}

The $\mathrm{pH}$ (both in water and in $\mathrm{KCl}$ ) was significantly lower $(P<0.01)$ and the TOC and $\mathrm{C} / \mathrm{N}$ values were significantly higher $(P<0.01)$ in the DIPLOS BSCs than in the other two types of BSCs. Moreover, the $\mathrm{pH}$ was significantly higher $(P<0.01)$ and the TOC was significantly lower $(P<0.01)$ in the CYANO BSCs than in the other types of BSCs. The water retention values at different $\mathrm{pF}$ values were very similar in all three types of BSCs (Table 1).

\subsection{Labile carbon pool and its components}

The amount of $\mathrm{C}$ extracted with hot water, i.e. the non-mineralized labile $\mathrm{C}$ (Table 2), was always highest $(P<0.01)$ in DIPLOS (in which it accounted for between $9.2 \%$ and $31.5 \%$ of the TOC) and lowest $(P<0.01)$ in CYANO (representing between $6.4 \%$ and $8.2 \%$ of the TOC). This fraction represented between $9.9 \%$ and $13.2 \%$ of the TOC in LEPRA. In all three types of crusts, the highest amount of $\mathrm{C}$ was extracted at a moisture content of $26.0 \%$ (Table 2). At higher moisture contents, this fraction always decreased significantly $(P<0.01)$ : the decreases were particularly strong in DIPLOS and the variations were much lower in CYANO and LEPRA (Table 2).

The biomass- $\mathrm{C}$ values at the end of the incubation period were always much higher $(P<0.01)$ in DIPLOS than in the other two types of crusts (Table 2). In general, the biomass-C values were highest at intermediate moisture contents (26-52.0\% for CYANO, 52\% for DIPLOS, and 26.0\% for LEPRA).

Emission of $\mathrm{CO}_{2}-\mathrm{C}$ at all moisture contents was significantly higher $(P<0.01)$ in DIPLOS than in the other two crusts, and the values were lowest in the CYANO BSCs. In all cases, the emission increased significantly $(P<0.01)$ with moisture content (Table 2$)$. The $\mathrm{CO}_{2}$ emissions were linearly related to the incubation time, and the values of the kinetic constant $(b)$ increased significantly $(P<0.01)$ with the moisture level (Fig. 2$)$.

For each type of BSC, the sum of the $\mathrm{C}$ extracted in hot water (the non-mineralized labile $\mathrm{C}$ fraction) and the $\mathrm{C}$ emitted as $\mathrm{CO}_{2}$, (mineralized labile $\mathrm{C}$ fraction) (Fig. 1) tended to increase as the moisture level increased, up to $52.0 \%$, although in DIPLOS, the value remained almost constant, except at the lowest moisture level considered (Table 2).

\subsection{Hydrolytic enzymes of the carbon cycle}

Both B-glucosidase activity and invertase activity were observed in all crusts, indicating the high capacity of the crusts to hydrolyze carbonaceous compounds (Fig. 3). At the lowest moisture level, the $\beta$-glucosidase activity was highest $(P<0.01)$ in LEPRA (Fig. 3), whereas at the highest moisture contents, the activity was highest $(P<0.01)$ in DIPLOS and lowest $(P<0.01)$ in CYANO. The $\beta$-glucosidase activity increased significantly $(P<0.01)$ with moisture content in DIPLOS and decreased significantly $(P<0.01)$ in CYANO (Fig. 3). The invertase activity was lowest $(P<0.01)$ in CYANO and was higher in DIPLOS and LEPRA, for which similar values were obtained (Fig. 3). The invertase activity increased significantly $(P<0.01)$ with moisture in DIPLOS, whereas in CYANO and LEPRA the value was maximal at a moisture content of $26 \%$ (Fig. 3). 
The ratio between invertase and $\beta$-glucosidase activity reflects the relative importance of the hydrolysis of sucrose and of glucosides. This ratio varied with moisture in different ways in the crusts predominated by cyanobacteria and in the crusts predominated by lichens (Fig. 3). In CYANO, the ratio increased with moisture content and tended towards a constant value, showing that as the moisture content increases, the cyanobacteria tend to use sucrose in preference to oligosaccharides. The opposite was observed in DIPLOS and LEPRA, i.e. there was a decrease in the ratio of invertase/ß-glucosidase activity as the moisture content increased (Fig. 3).

\subsection{Polyphenol and carbohydrate content of the hot water extract}

The content of hot water-soluble polyphenols was much higher $(P<0.01)$ in DIPLOS than in the other BSCs (Table 2). This fraction decreased sharply $(P<0.01)$ with increasing moisture content in DIPLOS, whereas it decreased gradually with increasing moisture content in LEPRA, and it varied slightly in CYANO (Table 2). In these two BSCs, the decreases in the polyphenol fraction as the moisture level increased were not significant $(P<0.01)$.

In all cases, the hot water fraction contained carbohydrates, and the carbohydrate content generally decreased $(P<0.01)$ with the moisture content (Table 2$)$. The predominant sugars were generally sucrose and glucose and, in many cases, mannitol was also important (Table 3). Other monosaccharides (possibly arabinose or xylose) appeared in minimal amounts. Sucrose and glucose tended to decrease with the moisture level, except in LEPRA, in which the sucrose tended to increase gradually with moisture, and in DIPLOS, in which there was a strong increase in glucose at $26 \%$ moisture (Table 3). In CYANO, sucrose was always present in higher amounts than glucose, whereas in DIPLOS, glucose was always present in higher amounts than sucrose, and in LEPRA different patterns were observed: at low moisture contents the amount of glucose was higher than the amount of sucrose (similarly to DIPLOS), and at higher moisture contents, the amount of sucrose was higher than that of glucose (similarly to CYANO) (Table 3).

\section{Discussion}

\section{1. $\mathrm{CO}_{2}-\mathrm{C}$ emissions and moisture content of the BSCs}

The strong increase in respiration in response to increased moisture indicates the presence of large amounts of mineralizable $\mathrm{C}$ forms in all of the BSCs, as previously observed (Amundson et al., 1989; Conant et al., 2000, 2004; Belnap et al., 2004; Thomas et al., 2011, among others). This was particularly evident in DIPLOS because at the highest moisture contents, almost $25 \%$ of the TOC was emitted as $\mathrm{CO}_{2}$ within only 10 days of incubation (Table 2). Such high emissions indicate that under suitable conditions of moisture and when photosynthetic activity is not taking place, there would be a high risk of loss of the TOC fixed in the BSCs, particularly in the BSCs formed by Diploschistes. These results (i.e. high losses of fixed C in BSCs due to strong increases in respiration under field conditions and after sufficient rainfall to moisten the crusts) are consistent with those of other studies (Conant et al., 2000, Collins et al., 2008; Almagro et al., 2009; Thomas et al., 2011).

The variation in $\mathrm{CO}_{2}$ emission with moisture content was described by a quadratic model, with correlation coefficients of one in almost all cases (Table 4), as also observed by Grote et al. 
(2010) and Castillo-Monroy et al. (2011). The structure of this equation and the sign of the coefficients (Table 4) indicate that respiration increases until the optimal moisture content (at which emission is maximal) and decreases thereafter. According to the values of the parameters obtained, the optimal moisture contents (expressed as percentages of water retained at $\mathrm{pF} 2$ ) are as follows: $100 \%$ for CYANO, 85\% for DIPLOS and 67\% for LEPRA. The value indicated for LEPRA is lower than the maximum moisture content used in the study (78\%), so that emission at a moisture content of $78 \%$ would be lower than the potential maximum. The occurrence of maxima at intermediate moisture contents, and the fact that this maximum is significantly higher $(P<0.01)$ in CYANO than in both lichen-dominated crusts, together confirm that the respiration decreases as the moisture content approaches saturation and that this effect is less evident in crusts predominated by cyanobacteria than in crusts predominated by lichens, as previously suggested (Grote et al., 2010). Independently of the above, the fact that this model is verified in all three types of crust enables calculation of the maximum amount of $\mathrm{CO}_{2}-\mathrm{C}$ that each crust can emit and of the moisture content at which the maximum emission occurs.

\subsection{Estimation of labile $C$ in the crusts}

In all of the crusts and for all moisture contents, the accumulated emission exhibited linear kinetics in relation to the incubation time, and the values of the kinetic constants increased significantly $(P<0.01)$ with moisture content (Fig. 2$)$. The linear relation between respiration and incubation time indicates zero order kinetics, or in other words, that the substrate is not limiting (Paul and Clark, 1989), so that the labile C pool is never exhausted in any crust or under any of the incubation conditions. This finding, which differentiates the crust layers of BSCs from the Ah horizons of soils, in which respiration usually follows first order kinetics (Paul and Clark, 1989), indicates the different lability of the organic matter of the BSCs relative to that of more evolved soils.

For all types of BSCs, the observed variations in the labile $\mathrm{C}$ contents in relation to moisture levels (Table 2) confirm that the labile $\mathrm{C}$ cannot be considered as a fixed parameter $(\mathrm{Hu}$ et al., 1997). However, in each of the three types of BSCs, the labile C tended towards a threshold value (towards which the sum of the emitted $\mathrm{C}$ and non-mineralized $\mathrm{C}$ tends), which appeared to represent the maximum amount of labile $\mathrm{C}$ that can be reached in a BSC. The maximum values of labile $\mathrm{C}$ estimated, considering the previous threshold value and the maximum emission that can be produced (deduced from the relation between emission and moisture content) in each type of crust were $2500 \mathrm{mg} \mathrm{kg}^{-1}$ for CYANO (16.7\% of the TOC), $17000 \mathrm{mg} \mathrm{kg}^{-1}$ for DIPLOS (38.8\% of the TOC) and $7200 \mathrm{mg} \mathrm{kg}^{-1}$ for LEPRA (19.7\% of the TOC). Both the absolute value and the percentage (relative to the TOC) of the maximum amount of labile $\mathrm{C}$ estimated were significantly lower in CYANO than in the lichen-dominated BSCs. This was surprising, as we expected to find a larger quantity of readily metabolizable compounds in the BSCs formed by cyanobacteria than in those formed by lichens. In the latter, a large part of the $\mathrm{C}$ must correspond to the products of fungal metabolism, possibly phenolic compounds, which are theoretically more recalcitrant than the carbohydrates synthesized by cyanobacteria. In other words, these findings do not only demonstrate the high metabolic potential of the BSCs formed by lichens, but also suggest the existence of different metabolic strategies in the crusts dominated by 
cyanobacteria and in those dominated by lichens. Moreover, the fact that almost $40 \%$ of the TOC in DIPLOS is labile C suggests that these BSCs should be considered as special ecosystems, capable of losing large amounts of fixed $\mathrm{C}$ under suitable conditions of moisture, with the negative implications that this has in relation to the role of BSCs as terrestrial C sinks.

Given that the biomass- $\mathrm{C}$ is included in the $\mathrm{C}$ extracted with hot water (i.e. it forms part of the non-mineralized labile $\mathrm{C}$ ), it is therefore feasible, for each type of crust and moisture level, to calculate the percentages of mineralized labile $\mathrm{C}$, the biomass- $\mathrm{C}$ and the remnant $\mathrm{C}$, in relation to the estimated maximum labile $\mathrm{C}$ (Fig. 4). For the highest moisture content tested, CYANO was clearly the BSC with the most remnant $\mathrm{C}$. In addition to other factors related to the biology of these formations, labile $\mathrm{C}$ may be retained because the moisture content (78\%) is still much lower than that at which respiration is maximal in these BSCs (100\% moisture). As regards the BSCs dominated by lichens, and the highest moisture content tested, DIPLOS used almost all of the labile $\mathrm{C}$ for respiration and biomass synthesis. However, in LEPRA, 20\% of the labile $\mathrm{C}$ was maintained as remnant $\mathrm{C}$, even at the highest moisture contents, as it was not used for either respiration or biomass synthesis. The laboratory conditions of the present study (constant darkness, temperature and moisture during 10 days) are very different from field conditions, in which the moisture does not remain constant for as long and photosynthetic processes interfere with decomposition processes. Nonetheless, the above findings suggest that of the BSCs dominated by lichens, the BSCs formed by Lepraria will lose less carbon than the other types of BSCs under a climate with a greater incidence of rainfall events than at present. Given that climate change predictions foresee an increase in rainfall events (IPCC W1, 2007), areas where Lepraria crusts occur should be conserved so that arid soils can continue to act as $\mathrm{C}$ sinks. In contrast, the sharp decrease in remnant $\mathrm{C}$ in DIPLOS with increasing moisture, at relatively low levels of between $26 \%$ and $52 \%$ (Fig. 4), confirms the poor functioning of these crusts as $\mathrm{C}$ sinks because, although they contain relatively large amounts of labile $\mathrm{C}$, the reserves of labile $\mathrm{C}$ are rapidly exhausted. Obviously, this reinforces the idea that the metabolic strategies in DIPLOS must be different from those in LEPRA.

\subsection{Metabolic strategies in the crusts in relation to moisture}

The variations in the $\beta$-glucosidase and invertase activities with moisture, as well as the ratio between these enzyme activities, suggest that at low moisture contents, metabolism in both lichen-dominated BSCs depends on sucrose, and at high moisture contents it depends on hydrolysis of oligosaccharides (Fig. 3). These differences may be due to the fact that sucrose is synthesized by autotrophic microorganisms, which in CYANO use the accumulated reserves because they cannot photosynthesize during respiration. In the crusts predominated by lichens, it may not be possible to utilize sucrose and it may be necessary to break down other carbohydrates or other organic compounds for metabolic purposes.

The type of extractable carbohydrates present provides more information about the metabolism of BSCs (Table 3). Independently of the metabolic activity in the crusts in relation to the moisture content, some simple sugars (mainly sucrose and glucose) always remain. The presence of these simple sugars even under conditions of intense respiration suggests that more complex substrates are being metabolized. This paradox (preferential use of substrates that are 
relatively difficult to degrade) can only be explained by considering that these simple sugars constitute a means of defence for the microorganisms in the crusts, and that their disappearance would lead to structural collapse of the crusts. This protective role for simple sugars is already known (Mager, 2010; Mager and Thomas, 2011) and appears essential even under situations of high physiological stress and when a large reduction in total labile $\mathrm{C}$ occurs. Surprisingly, these sugars did not include galactose, although this monosaccharide is known to be important as regards the protective role of sugars in BSCs (Brüll et al., 2000).

Sucrose remained in all crusts and at all moisture contents, but the variations in the concentrations indicate that some of the sucrose is hydrolyzed, which is consistent with the presence of invertase activity in all of the crusts. Although glucose (one of the products of the hydrolysis of sucrose) was always present, fructose (the other component of sucrose) was not found. One possible explanation for the absence of fructose is that it may have been metabolized in preference to other substrates and that when sucrose is hydrolysed, the fructose is rapidly metabolized. Another possible explanation is that the fructose had been reduced to produce mannitol, which would explain the presence of this polyalcohol in the BSCs studied. Mannitol exerts numerous beneficial effects on the organisms that synthesize it as it acts (i) as a carbohydrate reserve, (ii) as a translocatory compound, (iii) as an osmoregulatory compound, and (iv) in coenzyme regulation and to enable electron transport (Jennings, 1984; Wisselink et al., 2002). Mannitol is a well-known compatible solute, i.e. a component that protects organisms that are exposed to a number of stress situations (Iwamoto and Shiraiwa, 2005). In non photosynthesising organisms, it is formed from fructose by intracellular processes under situations of physiological stress and in the absence of sufficient intracellular oxygen brought about by high respiration rates (Jennings, 1984). The pathway of mannitol formation involves reduction of fructose and electron transport, and this mechanism is coupled to intracellular lactic acid fermentation. In the crusts under study, mannitol was present in lichen crusts (its presence in CYANO was minimal) and was present in highest amounts under conditions of low moisture, low respiration rates and obviously low stress (Table 6). This suggests that the main role of mannitol may be as an osmoregulator under conditions of low moisture (Wisselink et al., 2002), and its absence at high moisture contents suggests that it would be metabolized when the moisture conditions favour high rates of mineralization.

The polyphenol fraction, another component of the extract soluble in hot water and which is particularly abundant in DIPLOS, also appears to have an important function, which may explain the different metabolic strategy observed in this type of BSC. In the DIPLOS samples with low moisture contents, most of the non-mineralizable labile $\mathrm{C}$ consisted of polyphenols (Table 2). At high moisture contents, the polyphenols disappeared gradually, which suggests that polyphenols constitute a large proportion of the compounds that enable the very high rate of mineralization. This led us to consider the origin of these compounds and the mechanism of their catabolism. The polyphenol fraction may be associated with the proliferation (visually evident) of free-living fungi during the incubation period, as extraction with hot water would kill these organisms (Sparling et al., 1998; Leinweber et al., 1995). The disappearance of polyphenols at high moisture contents (Table 2) suggests the death of free-living fungi due to the scarcity of resources (possibly due to the lack of some essential element, such as $\mathrm{P}$ or $\mathrm{N}$, in the crusts), as well as to the presence of enzymes in the BSCs capable of degrading these remains. The 
degradation of polyphenols in BSCs is feasible, as several authors have indicated the presence of oxidative enzymes in crusts, such as polyphenol-oxidase, possibly stabilized on inorganic colloids (Stursova et al., 2006, Collins et al., 2008; Sinsabaugh, 2010). However, as the polyphenol fraction was estimated with the Folin-Ciocalteu reagent, and as other organic compounds such as proteins and aromatic amino acids also react positively to this reagent (Ceccanti et al., 1993), more detailed studies are required in order to elucidate the importance of polyphenols in lichen-predominated crusts.

\section{Conclusions}

This laboratory-based experiment enabled accurate estimation of the labile $\mathrm{C}$ present in BSCs and differentiation of the different components of this fraction. The maximum values of labile $\mathrm{C}$ indicate that between 17 and $39 \%$ of the TOC may be rapidly mineralized and enable estimation of the distribution of the labile $\mathrm{C}$ in the mineralized labile $\mathrm{C}$, biomass- $\mathrm{C}$ and remnant $\mathrm{C}$ fractions, for any moisture level.

Of the BSCs studied, those formed by cyanobacteria consume the lowest amounts of labile C. Of the BSCs constituted by lichens, those formed by Diploschistes appear to utilize most labile $\mathrm{C}$, as a result of the extremely high mineralization rate, whereas the crusts formed by Lepraria retain a greater proportion of the labile C. It would therefore appear that the conservation of BSCs formed by Lepraria is advisable in arid and semi-arid ecosystems.

The metabolic strategies appear to differ in the BSCs under study. The crust layers predominated by cyanobacteria appear to depend on sucrose hydrolysis, whereas hydrolysis of oligosaccharides appears to be favoured in the lichen-predominated crust layers.

Fructose was never found to be a constituent of the remnant labile $\mathrm{C}$ in the BSCs. The absence of fructose may be associated with the presence of mannitol, which indicates a metabolic pathway based on lactic acid fermentation in which fructose appears to play an essential role.

Although more detailed studies are required, the results indicate that polyphenols are used to maintain high rates of emission in DIPLOS, which suggests that this type of crust has the enzymatic potential to degrade these compounds.

As the crusts under study are mixed communities of organisms found in the field, and they are therefore truly representative of field communities, the results indicate that under arid or semi-arid conditions, a large part of the $\mathrm{C}$ accumulated in the crusts may be lost under conditions that favour strong mineralization, especially in the crusts predominated by lichens. These findings may be useful for predicting the effects of climate change on global $\mathrm{C}$ cycling, as they indicate that changes that involve more frequent and/or intense rainfall events would lead to a loss of the capacity of the crusts to act as $\mathrm{C}$ sinks.

\section{Acknowledgements}

The authors thank Ana I. Iglesias-Tojo for assistance in carrying out the analyses and Gonzalo Hermelo for help in identifying the carbohydrates by HPLC.

\section{References}


Almagro, M., López, J., Querejeta, J.J., Martínez-Mena, M., 2009. Temperature dependence of soil $\mathrm{CO}_{2}$ efflux is strongly modulated by seasonal patterns of moisture availability in a Mediterranean ecosystem. Soil Biology \& Biochemistry 41, 594-605.

Amundson, R.G., Chadwick, O.A., Sowers, J.M., 1989. A comparison of soil climate and biological activity along an elevational gradient in the eastern Mojave desert. Oecologia 80, 395-400.

Austin, A.T., Vivanco, L., 2006. Plant litter decomposition in a semi-arid ecosystem controlled by photodegradation. Nature 442, 555-558.

Belnap, J., Büdel, B., Lange, O.L., 2001. Biological soil crusts: characteristics and distribution. In: Belnap, J., Lange, O.L. (Eds.), Biological Soil Crusts, Structure, Function, and Management. Springer-Verlag, New York, pp 3-30.

Belnap, J., Phillips, S.L., Miller, M.E., 2004. Response of desert biological soil crusts to alterations in precipitation frequency. Oecologia 141, 306-316.

Borken, W., Matzner, E., 2009. Reappraisal of drying and wetting effects on $\mathrm{C}$ and $\mathrm{N}$ mineralisation and fluxes in soils. Global Change Biology 15, 808-824.

Brüll, L.P., Huang, Z., Thomas-Oates, J.E., Paulsen, B.S., Cohen, E.H., Michaelsen, T.E., 2000. Studies of polysaccharides from three edible species of Nostoc (cyanobacteria) with different colony morphologies: structural characterization and effect on the complement system of polysaccharides from Nostoc commune. Journal of Phycology 36, 871-881.

Castillo-Monroy, A.P., Maestre, F.T., Rey, A., Soliveres, S., García-Palacios, P., 2011. Biological soil crusts microsites are the main contributor to soil respiration in a semiarid ecosystem. Ecosystems 14, 835-847.

Ceccanti, B., Masciandaro, G., Garcia, C., 1993. Anaerobic digestion of straw and piggery waste water: I. Preliminary studies. Agrochimica XXXVII, 147-156.

Chinnici, F., Spinabelli, U., Amati, A., 2002. Simultaneous determination of organic acids, sugars, and alcohols in musts and wines by an improved ion-exclusion HPLC method. Journal of Liquid Chromatography \& Related Technologies 25, 2551-2560.

Collins, S.L., Sinsabaugh, R.L., Crenshaw, Ch., Green, L., Porras-Alfaro, A., Stursova, M., Zeglin, L.H., 2008. Pulse dynamics and microbial processes in aridland ecosystems. Journal of Ecology 96, 413-420.

Conant, R.T., Dalla-Betta, P., Klopatek, C.C., Klopatek, J.M., 2004. Controls on soil respiration in semiarid soils. Soil Biology \& Biochemistry 36, 945-951.

Conant, R.T., Klopatek, J.M., Klopatek, C.C., 2000. Environmental factors controlling soil respiration in three semiarid ecosystems. Soil Science Society of America Journal 64, 383390.

Eivazi, F., Tabatabai, M.A., 1988. Glucosidases and galactosidases in soils. Soil Biology \& Biochemistry 20, 601-606.

Fernandez, D.P., Neff, J.C., Belnap, J., Reynolds, R., 2006. Soil respiration in the cold desert environment of the Colorado Plateau (USA): abiotic regulators and thresholds. Biogeochemistry 78, 247-265.

Fierer, J., Schimel, J.P., 2003. A proposed mechanism for the pulse in carbon dioxide production commonly observed following the rapid rewetting of a dry soil. Soil Science Society of America Journal 67, 798-805. 
Grote, E., Belnap, J., Housman, D.C., Sparks, J.P., 2010. Carbon exchange in biological soil crust communities under differential temperatures and soil water contents: implications for global change. Global Change Biology 16, 2763-2774.

Guitián, F., Carballas, T., 1976. Técnicas de análisis de suelos. Ed. Pico Sacro, Santiago de Compostela.

Hu, S., Coleman, D.C., Carroll, C.R., Hendrix, P.F., Beare, M.H., 1997. Labile soil carbon pools in subtropical forest and agricultural ecosystems as influenced by management practices and vegetation types. Agriculture, Ecosystems and Environment 65, 69-78.

IPCC WG1, 2007. Climate Change: The Physical Science Basis. Cambridge University Press, Cambridge.

Iwamoto, K., Shiraiwa, Y., 2005. Salt-regulated mannitol metabolism in algae. Marine Biotechnology New York 7, 407-415.

Jennings, D. H., 1984. Polyol metabolism in fungi. Advances in Microbial Physiology 25, 149193.

Kuwatsova, S., Shindo, H., 1973. Behavoir of phenolic substances in the decaing process of plant. Identification and quantitative determination of phenolic acids in rice straw and its decayed products by gas cromatography. Soil Science Plant Nutrition 19, 219-27.

Landgraf, D., Wedig, S., Klose, S., 2005. Medium- and short-term available organic matter, microbial biomass, and enzyme activities in soils under Pinus sylvestris L. and Robinia pseudoacacia L. in a sandy soil in NE Saxony, Germany. Journal of Plant Nutrition and Soil Science 168, 193-201.

Leinweber, P., Schulten, H.R., Körschens, M., 1995. Hot water extracted organic matter: chemical composition and temporal variations in a long-term field experiment. Biology and Fertility of Soils 20, 17-23.

Luo, Y., Zhou, X., 2006. Soil Respiration and the Environment. Academic Press, London.

Maestre, F.T., Bowker, M.A., Cantón, Y., Castillo-Monroy, A.P., Cortina, J., Escolar, C., Escudero, A., Lázaro, R., Martínez, I., 2011. Ecology and functional roles of biological soil crust in semi-arid ecosystems of Spain. Journal of Arid Environments 75, 1282-1291.

Mager, D.M., 2010. Carbohydrates in cyanobacterial soil crusts as a source of carbon in the southwest Kalahari, Botswana. Soil Biology \& Biochemistry 42, 313-318.

Mager, D.M., Thomas, A.D., 2011. Extracellular polysaccharides from cyanobacterial soil crusts: A review of their role in dryland soil processes. Journal of Arid Environments 75, 9197.

Miralles, I., Domingo, F., Cantón, Y., Trasar-Cepeda, C., Leirós, M.C., Gil-Sotres, F., 2012. Hydrolase enzyme activities in a successional gradient of biological soil crusts in arid and semi-arid zones. Soil Biology \& Biochemistry 53, 124-132.

Paul, E.A., Clark, E.F., 1989. Soil Microbiology and Biochemistry. Academic Press, London.

Rovira, P., Vallejo, V.R., 2002. Labile and recalcitrant pools of carbon and nitrogen in organic matter decomposing at different depths in soil: an acid hydrolysis approach. Geoderma 107, $109-141$

Schinner, F. and von Mersi, W., 1990. Xylanase-, CM-cellulase- and invertase activity in soil: an improved method. Soil Biology \& Biochemistry 22, 511-515. 
Sinsabaugh, R.L., 2010. Phenol oxidase, peroxidase and organic matter dynamics of soil. Soil Biology \& Biochemistry 42, 391-404.

Sparling, G., Vojvodić-Vuković, M., Schipper, L.A., 1998. Hot-water soluble C as a simple measure of labile soil organic matter: the relationship with microbial biomass C. Soil Biology \& Biochemistry 30, 1469-1472.

Speir, T.W., Cowling, J.C., Sparling, G.P., West, A.W., Corderoy, D.M., 1986. Effects of microwave radiation on the microbial biomass, phosphatase activity and the levels of extractable $\mathrm{N}$ and $\mathrm{P}$ in a low fertility soil under pasture. Soil Biology \& Biochemistry 18, 377-382.

Sponseller, R.A., Fisher, S.G., 2008. The influence of drainage networks on patterns of soil respiration in a desert catchment. Ecology 89, 1089-1100.

Stanier, R.Y., Douderoff, M., Adelberg, E.A., 1968. General Microbiology, MacMillan, London.

Stursova, M., Crenshaw, Ch.L., Sinsabaugh, R.L., 2006. Microbial responses to long-term N deposition in a semiarid grassland. Microbial Ecology 51, 90-98.

Stursova, M., Sinsabaugh, R.L., 2008. Stabilization of oxidative enzymes in desert soil may limit organic matter accumulation. Soil Biology \& Biochemistry 40, 550-553.

Thomas, A.D., Hoon, S.R., Dougill, A.J., 2011. Soil respiration at five sites along the Kalahari Transect: Effects of temperature, precipitation pulses and biological soil crust cover. Geoderma 167-168, 284-294.

Vance, E.D., Brookes, P.C., Jenkinson, D.S., 1987. An extraction method for measuring soil microbial biomass carbon. Soil Biology \& Biochemistry 19, 703-707.

Wisselink, H.W., Weusthuis, R.A., Eggink, G., Hugenholtz, J., Grobben, G.J., 2002. Mannitol production by lactic acid bacteria: a review. International Dairy Journal 12, 151-161. 
Table 1. General properties of the crust samples studied. For each property, different lower case letters indicate that mean values for each type of BSC are significantly different $(P<0.01)$.

\begin{tabular}{|c|c|c|c|c|c|c|c|c|}
\hline & pH water & pH KCl & $\begin{array}{l}\text { TOC } \\
\mathrm{g} \mathrm{kg}^{-1}\end{array}$ & $\begin{array}{c}\mathrm{TN} \\
\mathrm{g} \mathrm{kg}^{-1}\end{array}$ & $\mathrm{C} / \mathrm{N}$ & $\begin{array}{l}\text { water content pF } 2 \\
\qquad \mathrm{~g} \mathrm{~kg}^{-1}\end{array}$ & $\begin{array}{l}\text { water content pF } 4.2 \\
\qquad \mathrm{~g} \mathrm{~kg}^{-1}\end{array}$ & $\begin{array}{l}\text { field moisture } \\
\qquad \mathrm{g} \mathrm{kg}^{-1}\end{array}$ \\
\hline CYANO & $7.7 \pm 0.1 a$ & $6.9 \pm 0.1 a$ & $15.0 \pm 1.5 a$ & $1.6 \pm 0.1 a$ & $9.4 \pm 1.5 \mathrm{a}$ & $360 \pm 18 a$ & $103 \pm 23 a$ & $29.0 \pm 1.0 a$ \\
\hline DIPLOS & $6.7 \pm 0.1 b$ & $6.0 \pm 0.1 b$ & $43.8 \pm 4.4 b$ & $2.1 \pm 0.2 b$ & $20.8 \pm 2.2 b$ & $397 \pm 28 a$ & $151 \pm 27 a$ & $35.3 \pm 2.1 b$ \\
\hline LEPRA & $7.0 \pm 0.1 c$ & $6.6 \pm 0.1 c$ & $36.5 \pm 2.2 c$ & $3.2 \pm 0.3 c$ & $11.4 \pm 4 \mathrm{a}$ & $398 \pm 12 a$ & $150 \pm 24 a$ & $46.6 \pm 1.5 c$ \\
\hline
\end{tabular}


Table 2. Values $\left(\mathrm{mg} \mathrm{kg}^{-1}\right.$ ) of non-mineralized $\mathrm{C}$ (total $\mathrm{C}$, carbohydrate $\mathrm{C}$ and polyphenol $\mathrm{C}$ ), biomass- $\mathrm{C}, \mathrm{CO}_{2}-\mathrm{C}$ emitted and labile $\mathrm{C}$ (sum of nonmineralized $\mathrm{C}$ and $\mathrm{CO}_{2}-\mathrm{C}$ emitted), at the end of the 10-day incubation period at the different moisture contents (\% $\mathrm{M}$, moisture as a percentage of water retained $\mathrm{pF}$ 2). For each property, different capital letters indicate that mean values at the same moisture content of different BSCs are significantly different $(\mathrm{P}<0.01)$; for each property and type of $\mathrm{BSC}$, different lower case letters indicate that mean values at the different moisture contents are significantly different $(\mathrm{P}<0.01)$.

\begin{tabular}{|c|c|c|c|c|c|c|}
\hline \multirow[t]{2}{*}{$\% \mathbf{M}$} & \multicolumn{3}{|c|}{ Non-mineralized C } & \multirow{2}{*}{ Biomass-C } & \multirow{2}{*}{$\mathrm{CO}_{2}-\mathrm{C}$ emitted } & \multirow[t]{2}{*}{ Labile C } \\
\hline & Total C & Earbohydrate C & Polyphenol C & & & \\
\hline \multicolumn{7}{|l|}{ CYANO } \\
\hline 9.6 & $A 1206 \pm 17 a$ & $A 302 \pm 1 a$ & $A 166 \pm 19 a$ & $A 678 \pm 42 a$ & $A 111 \pm 16 a$ & $A 1317 \pm 33 a$ \\
\hline 26.0 & $A 1234 \pm 9 a$ & $A 201 \pm 3 b$ & $A 154 \pm 15 a$ & $A 750 \pm 19 b$ & $A 426 \pm 17 b$ & $A 1660 \pm 26 b$ \\
\hline 52.0 & $A 1213 \pm 9 a$ & $A 159 \pm 4 c$ & $A 200 \pm 7 b$ & $A 755 \pm 12 b$ & $A 740 \pm 20 c$ & $A 1953 \pm 29 c$ \\
\hline 78.0 & $A 963 \pm 22 b$ & $A 134 \pm 5 d$ & $A 146 \pm 14 a$ & $A 673 \pm 18 a$ & $A 1008 \pm 33 d$ & $A 1971 \pm 55 c$ \\
\hline \multicolumn{7}{|l|}{ DIPLOS } \\
\hline 9.6 & $B 12545 \pm 386 a$ & $B 788 \pm 7 a$ & $B 11757 \pm 225 a$ & $B 1731 \pm 86 a$ & $B 775 \pm 27 a$ & $B 13320 \pm 413 a$ \\
\hline 26.0 & $B 13802 \pm 296 b$ & $B 1575 \pm 6 b$ & $B 12227 \pm 40 b$ & $B 2693 \pm 75 b$ & $B 2907 \pm 98 b$ & $B 16709 \pm 394 b$ \\
\hline 52.0 & $B 6259 \pm 268 c$ & $B 467 \pm 6 c$ & $B 5268 \pm 267 c$ & $B 4518 \pm 73 c$ & $B 8966 \pm 364 c$ & $B 15225 \pm 632 c$ \\
\hline 78.0 & $B 4019 \pm 116 d$ & $B 345 \pm 17 c$ & $B 1041 \pm 130 d$ & $B 3451 \pm 65 b$ & $B 11125 \pm 416 d$ & $B 15144 \pm 532 c$ \\
\hline \multicolumn{7}{|l|}{ LEPRA } \\
\hline 9.6 & $C 4221 \pm 116 a$ & $C 336 \pm 4 a$ & $C 562 \pm 44 a$ & $C 1526 \pm 54 a$ & $C 569 \pm 16 a$ & $\mathrm{C} 4790 \pm 132 a$ \\
\hline 26.0 & $C 4804 \pm 27 b$ & $C 319 \pm 2 b$ & $C 376 \pm 27 b$ & $C 2355 \pm 66 b$ & $C 1434 \pm 41 b$ & $C 6238 \pm 68 b$ \\
\hline 52.0 & $C 3765 \pm 30 c$ & $C 283 \pm 10 c$ & $C 379 \pm 19 b$ & $C 2202 \pm 98 b c$ & $C 3027 \pm 86 c$ & $C 6792 \pm 116 c$ \\
\hline 78.0 & $C 3604 \pm 16 d$ & $C 298 \pm 6 c$ & $C 369 \pm 57 b$ & $C 2106 \pm 55 c$ & $C 3507 \pm 100 d$ & $C 7111 \pm 116 c$ \\
\hline
\end{tabular}


Table 3. Content of different sugars $\left(\mathrm{mg} \mathrm{C} \mathrm{kg}^{-1}\right)$ in the hot water extracts obtained at the end of the incubation period $(\% \mathrm{M}$, moisture as a percentage of water retained at $\mathrm{pF} 2$. For each property, different capital letters indicate that mean values at the same moisture content of different BSCs are significantly different $(\mathrm{P}<0.01)$; for each property and type of BSC, different lower case letters indicate that mean values at the different moisture contents are significantly different $(\mathrm{P}<0.01)$.

\begin{tabular}{ccccc}
\hline \% M & Sucrose & Glucose & Mannitol & Others $^{\#}$ \\
\hline CYANO & & & & \\
9.6 & $A 211 \pm 11 a$ & $A 84 \pm 7 a$ & $A 0 \pm 0 a$ & $A 7 \pm 1 a$ \\
$\mathbf{2 6 . 0}$ & $A 139 \pm 9 b$ & $A 52 \pm 6 b$ & $A 6 \pm 1 b$ & $A 4 \pm 1 b$ \\
$\mathbf{5 2 . 0}$ & $A 105 \pm 10 c$ & $A 44 \pm 3 c$ & $A 8 \pm 1 b$ & $A 2 \pm 0 c$ \\
$\mathbf{7 8 . 0}$ & $A 88 \pm 3 c$ & $A 44 \pm 3 c$ & $A 2 \pm 0 c$ & $A 0 \pm 0 d$ \\
DIPLOS & & & & \\
$\mathbf{9 . 6}$ & $B 319 \pm 20 a$ & $B 460 \pm 15 a$ & $A 0 \pm 0 a$ & $A 9 \pm 1 a$ \\
$\mathbf{2 6 . 0}$ & $B 230 \pm 16 b$ & $B 1276 \pm 95 b$ & $B 44 \pm 2 b$ & $B 25 \pm 2 b$ \\
$\mathbf{5 2 . 0}$ & $A 106 \pm 11 c$ & $B 320 \pm 30 c$ & $B 41 \pm 1 b$ & $A 0 \pm 0 c$ \\
$\mathbf{7 8 . 0}$ & $\mathrm{A} 94 \pm 6 c$ & $B 240 \pm 16 d$ & $B 11 \pm 1 c$ & $\mathrm{~A} 0 \pm 0 c$ \\
LEPRA & & & & \\
$\mathbf{9 . 6}$ & $C 108 \pm 11 a$ & $C 132 \pm 9 a c$ & $C 72 \pm 8 a$ & $B 24 \pm 2 a$ \\
$\mathbf{2 6 . 0}$ & $A 118 \pm 10 a$ & $C 142 \pm 10 a$ & $B 49 \pm 5 b$ & $C 10 \pm 3 b$ \\
$\mathbf{5 2 . 0}$ & $C 150 \pm 13 b$ & $C 94 \pm 14 b$ & $A 14 \pm 2 c$ & $B 25 \pm 2 a$ \\
$\mathbf{7 8 . 0}$ & $C 145 \pm 12 b$ & $C 118 \pm 7 b c$ & $C 25 \pm 2 d$ & $B 10 \pm 2 b$ \\
\hline
\end{tabular}

\#, mainly arabinose and xylose 
Table 4. Fit of the emission data to the quadratic model $Y=\mathrm{a}+\mathrm{b} m+\mathrm{c} m^{2}\left(Y, \mathrm{CO}_{2}-\mathrm{C}\right.$ emitted $\mathrm{mg} \mathrm{kg}^{-1} 10$ days $^{-1}$; $m$, moisture content).

\begin{tabular}{lcccc}
\hline & $\boldsymbol{r}$ & $\mathbf{a}$ & $\mathbf{b}$ & $\mathbf{c}$ \\
\hline CYANO & $1.00 * * *$ & -57 & 62.41 & -0.87 \\
DIPLOS & $0.99 * * *$ & -2658 & 851.86 & -12.68 \\
LEPRAS & $1.00 * * *$ & -811 & 326.08 & -6.13 \\
\hline
\end{tabular}

$* * * P \leq 0.001$ 


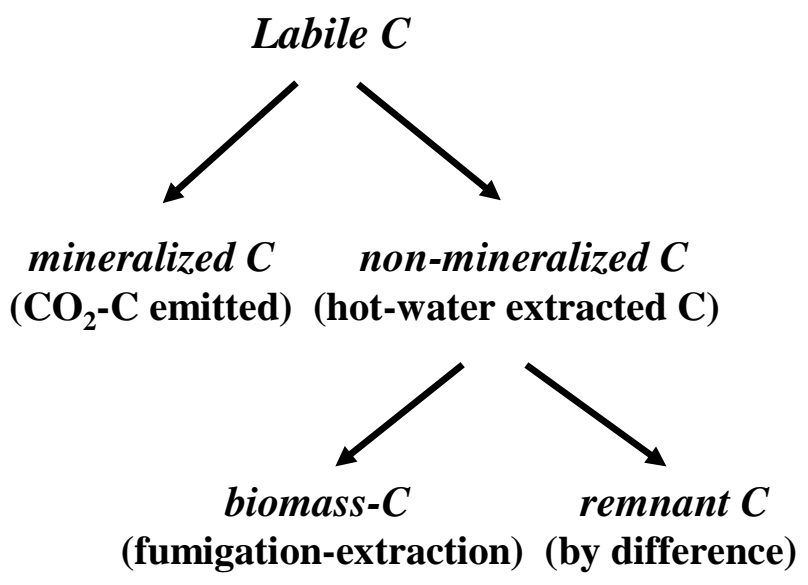

Fig. 1. Distribution of the labile $\mathrm{C}$ in the fractions considered, after incubation of samples in the dark and under controlled conditions of moisture and temperature. 

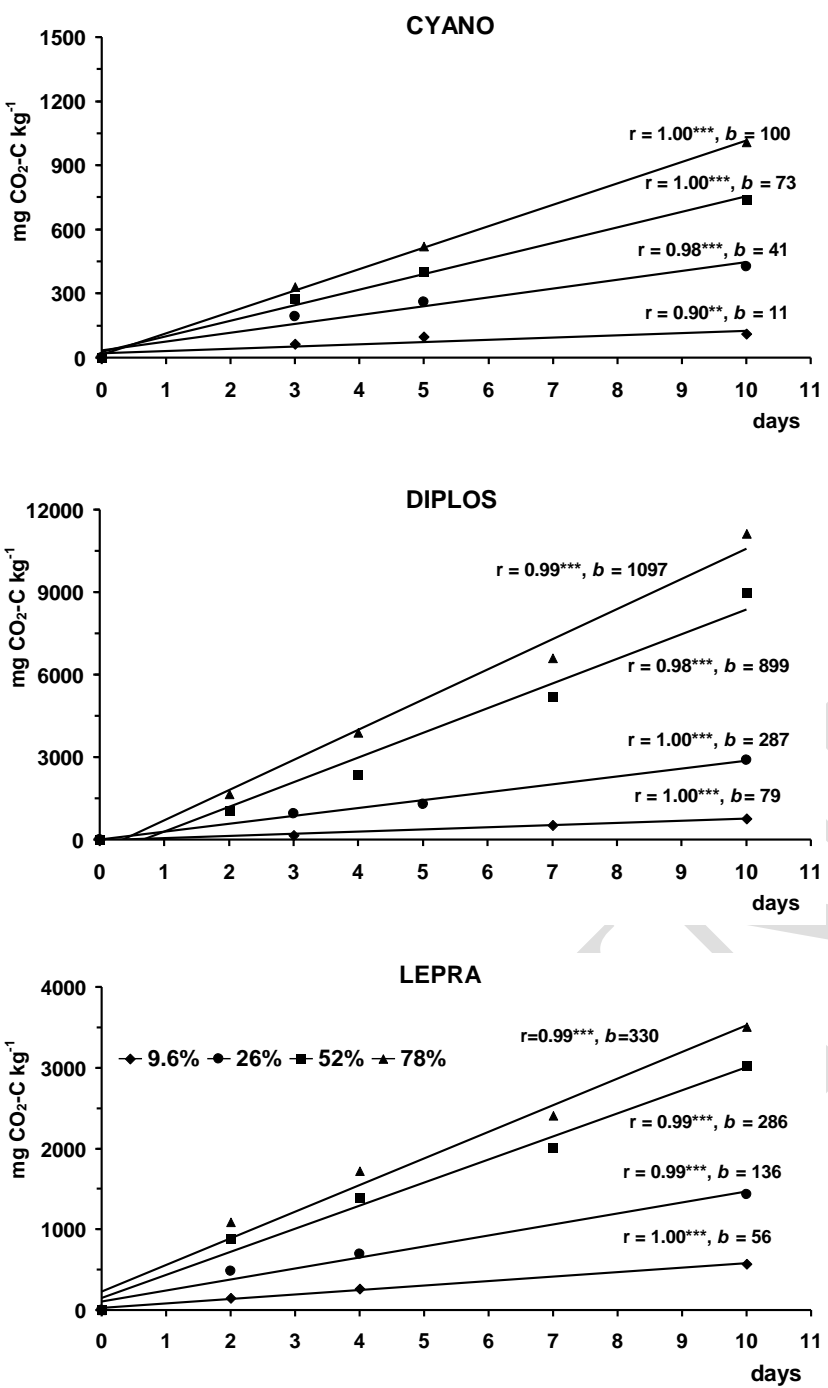

Fig. 2. Fit of the emission data accumulated throughout the incubation period to a linear kinetic model in each type of crust and for each moisture level (\% M, moisture expressed as a percentage of water retained at $\mathrm{pF} 2$ ). 

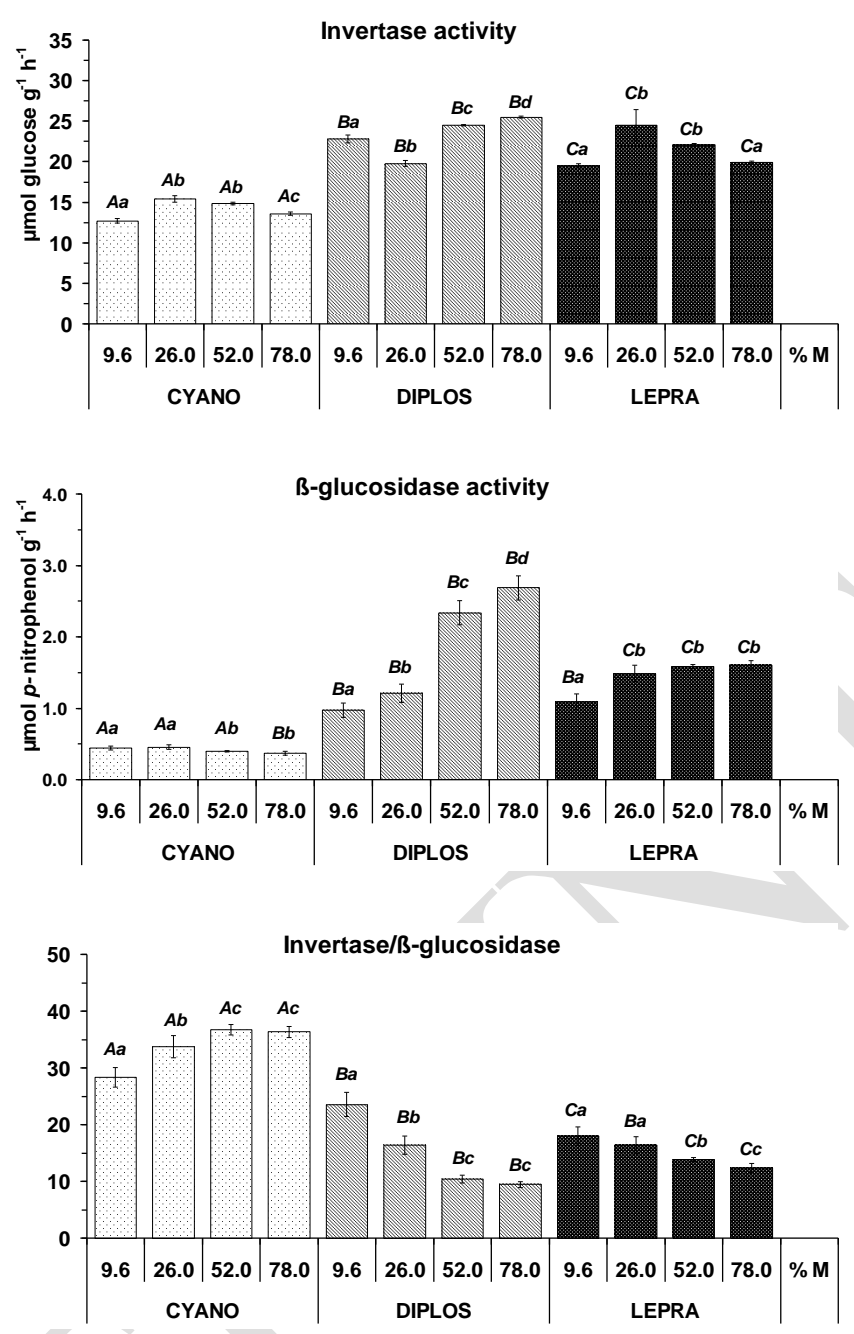

Fig. 3. Variations in the invertase and $B$-glucosidase activities and in the ratio between invertase and B-glucosidase activities for each type of crust and moisture level. For each property, different capital letters indicate that mean values at the same moisture content in different BSCs are significantly different $(P<0.01)$; for each property and type of BSC, different lower case letters indicate that mean values at the different moisture contents are significantly different $(P<0.01)$. 

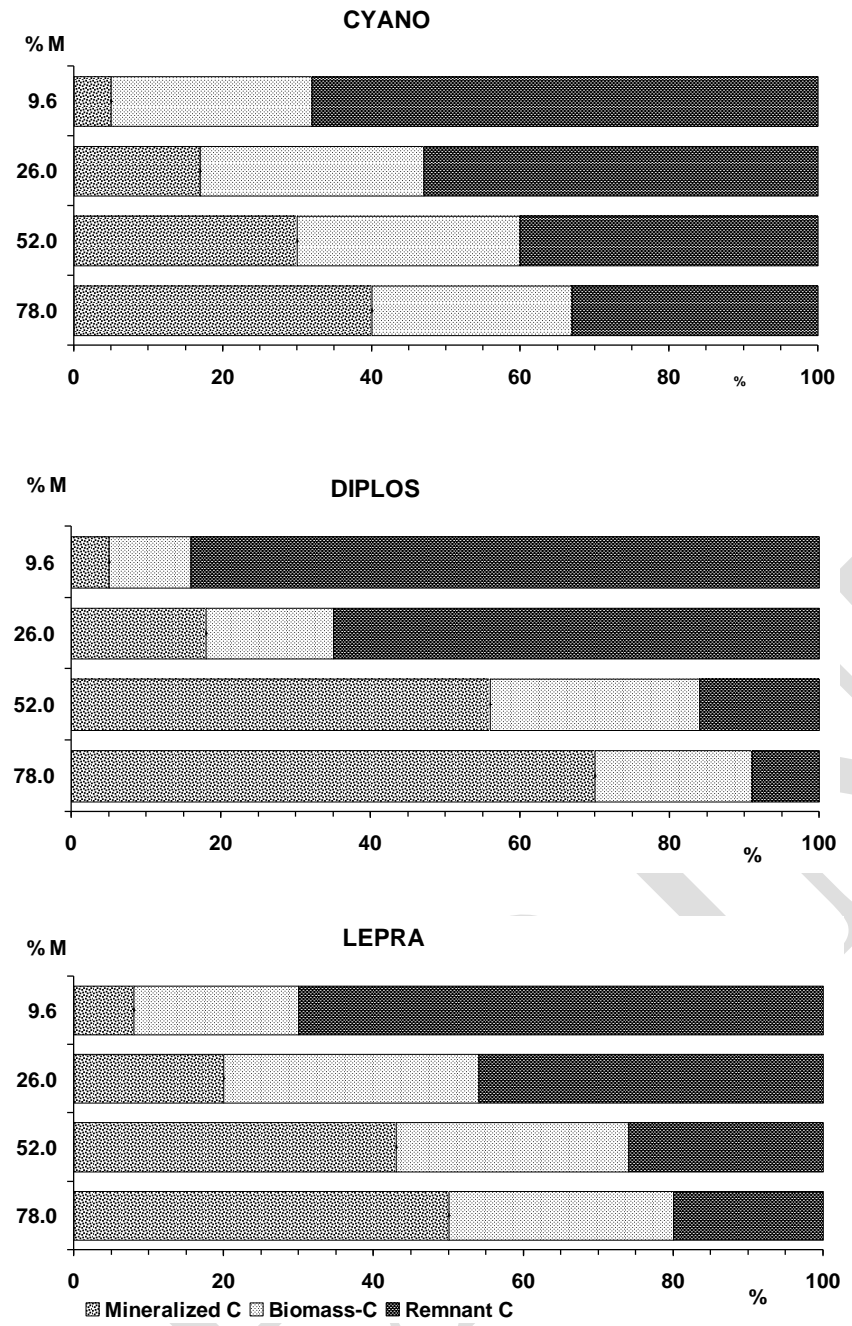

Fig. 4. Percentage distribution of the labile $\mathrm{C}$ fractions (biomass- $\mathrm{C}$, mineralized $\mathrm{C}$ and remnant $\mathrm{C}$ ) in each type of crust and for each moisture level (\% $\mathrm{M}$, moisture expressed as a percentage of water retained at $\mathrm{pF} 2$ ). 